\title{
Kinetics and Mechanisms of Permanganate Oxidations of Cadaverine in Different Media
}

\author{
Ahmed Fawzy ${ }^{1,2, ~ *, ~ I s h a q ~ A . ~ Z a a f a r a n y ~}{ }^{1}$, Metwally Abdallah ${ }^{1,3}$, Rabab S. Jassas ${ }^{1}$, Rami J. Obaid ${ }^{1}$ \\ ${ }^{1}$ Chemistry Department, Faculty of Applied Science, Umm Al-Qura University, Makkah, Saudi Arabia \\ ${ }^{2}$ Chemistry Department, Faculty of Science, Assiut University, Assiut, Egypt \\ ${ }^{3}$ Chemistry Department, Faculty of Science, Benha University, Benha, Egypt
}

\section{Email address:}

afsaad13@yahoo.com (A. Fawzy), iazaafarany@uqu.edu.sa (I. A. Zaafarany), metwally555@yahoo.com (M. Abdallah), rabab-j@hotmail.com (R. S. Jassas), rjobaid@uqu.edu.sa (R. J. Obaid)

${ }^{*}$ Corresponding author

\section{To cite this article:}

Ahmed Fawzy, Ishaq A. Zaafarany, Metwally Abdallah, Rabab S. Jassas, Rami J. Obaid. Kinetics and Mechanisms of Permanganate Oxidations of Cadaverine in Different Media. American Journal of Physical Chemistry. Vol. 5, No. 6, 2016, pp. $108-117$. doi: $10.11648 /$ j.ajpc.20160506.12

Received: November 16, 2016; Accepted: November 23, 2016; Published: December 23, 2016

\begin{abstract}
The kinetics of oxidation of cadaverine (CAD) by permanganate ion in acidic, neutral and alkaline media has been investigated spectrophtometrically at constant ionic strengths and temperature. The reactions in different media exhibited a first order kinetics in $\left[\mathrm{MnO}_{4}{ }^{-}\right]$and less than unit order dependences with respect to [CAD]. The oxidation of cadaverine showed less than unit order dependences with respect to $\left[\mathrm{H}^{+}\right]$and $\left[\mathrm{OH}^{-}\right]$in acidic and alkaline media, respectively. Variation of ionic strengths in both acidic and alkaline media had no significant effect on the oxidation rates. The proposed oxidations mechanisms in all media involve formation of 1:1 intermediate complexes between the kinetically active species of both cadaverine and permanganate ion. The final oxidation products of cadaverine were identified as 5-aminopentanal and ammonia. The appropriate rate laws in all media were deduced. The reaction constants involved in the different steps of the mechanisms were evaluated.
\end{abstract}

Keywords: Cadaverine, Permanganate, Oxidation, Kinetics, Mechanism

\section{Introduction}

Polyamines are widely distributed in living organisms and are known to be essential elements for normal growth and development. Cadaverine (1,5-pentanediamine) is a foulsmelling toxic diamine compound produced by protein hydrolysis during putrefaction of animal tissue [1]. It is also produced in small quantities by living beings. It is partially responsible for the distinctive odors of urine. The odor commonly associated with bacterial vaginosis has been linked to cadaverine and putrescine [2].

Oxidation reactions are significant field in organic synthesis. Permanganate ion is an efficient oxidant in acidic, neutral and alkaline media [3-17] which still remains as one of the most important and eco-friendly multi-electron oxidants employed in the kinetic studies. The mechanism of oxidation by this multivalent oxidant depends not only on the substrate but also on the medium used for the study.

The literature review revealed that there is no reports on the kinetics of oxidation of cadaverine by any oxidant. This observation prompted us to investigate the title reactions which represent a full kinetic study on the oxidations of cadaverine by permanganate ion in different media in order to establish the optimum conditions affecting such oxidation reactions, to understand the different kinetically active species of the reactants in these media, and finally to elucidate plausible oxidations mechanisms on the basis of the obtained kinetic and spectral results.

\section{Experimental}

\subsection{Materials}

The stock solution of cadaverine was prepared by dissolving the appropriate amount of the sample (Sigma) in 
the required volume of double distilled water. Solution of potassium permanganate was prepared and standardized as reported earlier [18]. Perchloric acid, sodium hydroxide and sodium perchlorate solutions were used to provide the required acidity, alkalinity and ionic strength, respectively. Potassium phosphate buffer (Sigma-Aldrich) was also employed to keep the neutral medium $(\mathrm{pH}=7.0)$. Other chemicals were from Merck or Sigma.

\subsection{Kinetic Measurements}

All kinetic measurements were carried out under pseudofirst order conditions where a large excess of cadaverine over permanganate was present. The ionic strengths in both acidic $\left(2.0 \mathrm{~mol} \mathrm{dm}^{-3}\right)$ and alkaline $\left(0.2 \mathrm{~mol} \mathrm{dm}^{-3}\right)$ media were maintained constant using sodium perchlorate as an inert electrolyte. The reactions temperature $\left(25^{\circ} \mathrm{C}\right)$ was controlled within $\pm 0.1^{\circ} \mathrm{C}$. The courses of the oxidation reactions in all media was followed by monitoring the decrease in the absorbance of permanganate ion, as a function of time, at $\lambda=525 \mathrm{~nm}$, its absorption maximum, on a thermostatted Shimadzu UV-VIS-NIR-3600 double-beam spectrophotometer.

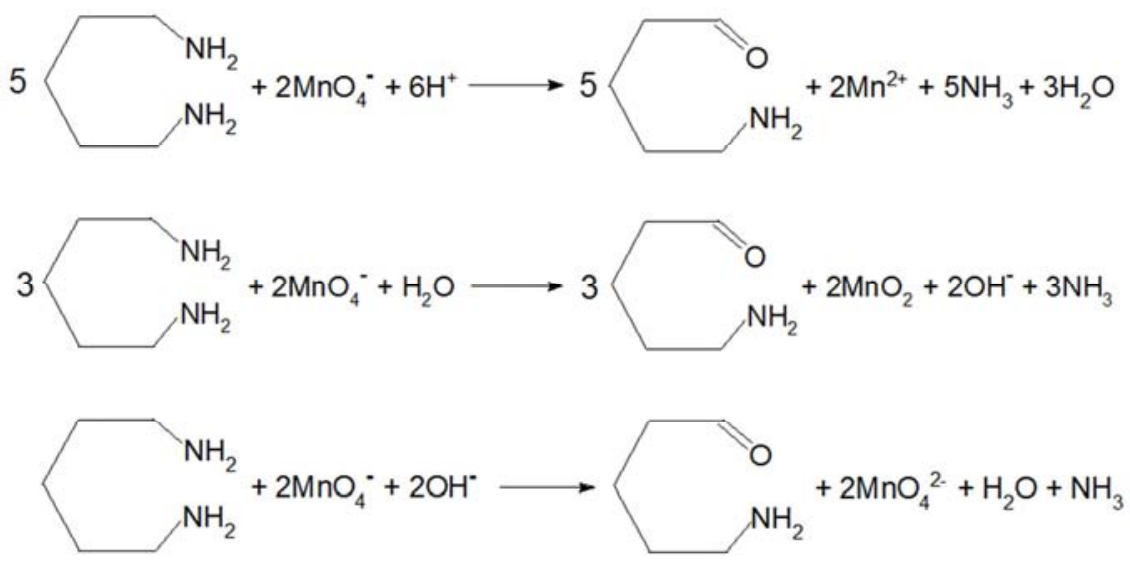

Scheme 1. Oxidation of cadaverine by permanganate ion in: (1) acidic, (2) neutral and (3) alkaline media.

The products were identified as the corresponding aldehyde (5-aminopentanal) by liquid chromatography (HPLC) and by spot test [19] and ammonia by Nessler's reagent [20]. The product, 5-aminopentanal was also estimated quantitatively as its 2, 4-dinitrophenylhydrazone derivative [20].

\subsection{Spectroscopic Studies}

Spectral changes throughout permanganate oxidations of cadaverine in acidic, neutral and alkaline media are shown in Fig 1 (a), (b) and (c), respectively. In all media, there isa gradual disappearance of the band of permanganate ion at $\lambda=525 \mathrm{~nm}$. In both neutral and alkaline media, new absorption bands were appeared at wavelengths above 600 $\mathrm{nm}$. Also, in alkaline medium two isosbestic points were appeared at wavelengths of about 579 and $473 \mathrm{~nm}$ while in neutral medium only one isosbestic point was appeared at about $478 \mathrm{~nm}$.
The observed first order rate constants $\left(k_{\mathrm{obs}}\right)$ were calculated as the slopes of $\ln$ (absorbance)-time plots. Average values of at least two kinetic runs of the rate constants were taken. The rate constants were reproducible to within $3 \%$. The orders of the reactions with respect to the reactants were determined from the plots of $\log k_{\text {obs }}$ versus $\log$ (conc.) by varying the concentrations of cadaverine, perchloric acid and sodium hydroxide, in turn, while keeping other reactants constant.

\section{Results and Discussion}

\subsection{Reactions Stoichiometries and Products Identification}

Various sets of the reactions mixtures in different media containing different ratios of permanganate to cadaverine were mixed at constant $\mathrm{pH}$ and ionic strength, then were kept for about 24 hours. The remaining permanganate concentrations was determined spectrophotometrically which confirm that the stoichiometry was 5: 2 in perchloric acid, 3: 2 in neutral and 1: 2 in alkaline medium which holds by the following equations (Scheme 1), 


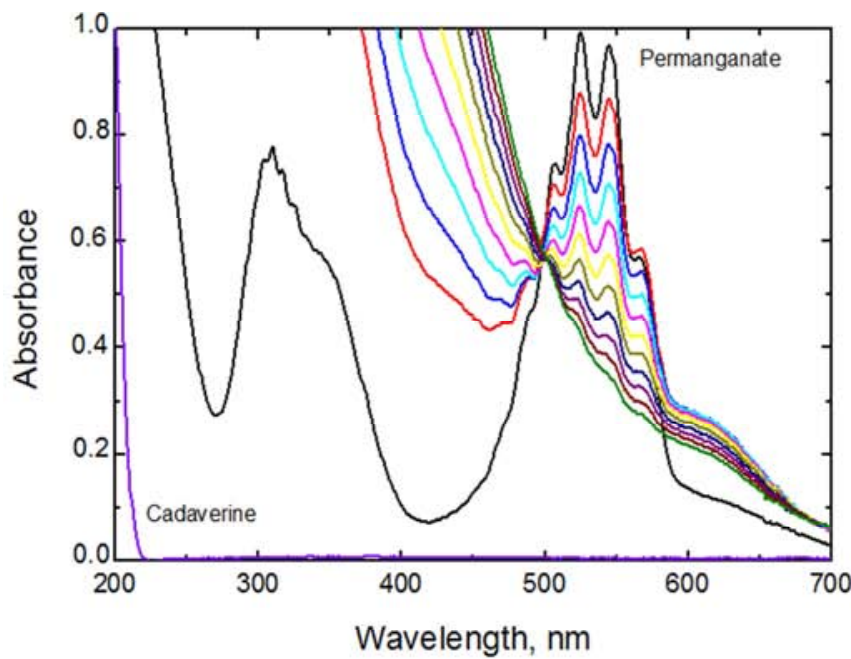

(b)

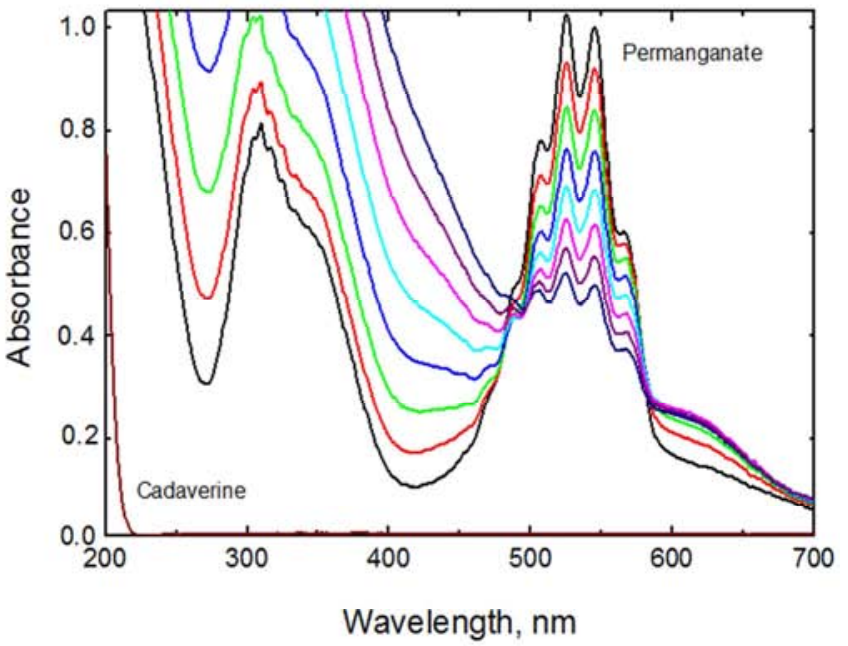

(c)

Figure 1. Spectroscopic changes throughout permanganate oxidations of cadaverine in: (a) perchloric acid medium, $\left[\mathrm{H}^{+}\right]=1.0$ and $\mathrm{I}=2.0 \mathrm{~mol}$ dm ${ }^{-3}$, (b) neutral medium, and (c) sodium hydroxide medium, $\left[\mathrm{OH}^{-}\right]=0.1, \mathrm{I}=0.2 \mathrm{moldm}^{-3}$. [CAD] $=6.0 \times 10^{-3},\left[\mathrm{MnO}_{4}^{-}\right]=4.0 \times 10^{-4} \mathrm{~mol} \mathrm{dm}^{-3} \mathrm{at} 25^{\circ} \mathrm{C}^{-}$

\subsection{Effect of $\left[\mathrm{MnO}_{4}^{-}\right]$on the Oxidation Rates}

The effect of permanganate ion oxidant on the oxidation rates in all three media was studied by varying its concentration in the range of $(2.0-10.0) \times 10^{-4} \mathrm{~mol} \mathrm{dm}^{-3}$ at fixed concentrations of other reactants and at constant ionic strength and temperature. The order with respect to $\left[\mathrm{MnO}_{4}{ }^{-}\right]$ was found to be unity in all media, as plots of $\ln$ (absorbance) versus time were linear up to about two half-lives of the reactions completion. The first order dependence of the reactions on $\left[\mathrm{MnO}_{4}^{-}\right]$was also confirmed by the nonvariation of the observed-first order rate constants $\left(k_{\text {obs }}\right)$ at various $\left[\mathrm{MnO}_{4}{ }^{-}\right]$as listed in Table 1 (for the neutral medium as an example).

\subsection{Effect of [CAD] on the Oxidation Rates}

It was found that with increasing the concentration of cadaverine reductant the oxidation rates were also increased in all media as listed in Table 1. Plots of $k_{\mathrm{obs}}$ versus [CAD] were found to be linear with positive intercepts on $k_{\text {obs }}$ axes as shown in Fig. 2 suggesting that the ordersof the reactions with respect to $[\mathrm{CAD}]$ were less than unity.

\subsection{Effect of $\mathrm{pH}$ on the Oxidation Rates}

The effect of $\mathrm{pH}$ of the reactions mediaon theoxidation rates was investigated by performing the kinetic runs at various hydrogen ion concentrationsin the range of $0.2-1.8$ moldm ${ }^{-3}$ using perchloric acid in acid medium, and at various hydroxyl ion concentrations $\left(0.02-0.18\right.$ moldm $\left.^{-3}\right)$ using sodium hydroxide in alkaline medium, while keeping the concentrations of all other reactants constant. It was observed that the oxidation rates of the reactions in both acidic and alkaline media were found to increase with increasing $\left[\mathrm{H}^{+}\right]$ and $\left[\mathrm{OH}^{-}\right]$, respectively, as listed in Table 1 . The orders of the reactions with respect to $\left[\mathrm{H}^{+}\right]$and $\left[\mathrm{OH}^{-}\right]$were found to be less than unity as the gradients of the plots of $\log k_{\text {obs }}$ versus $\log \left[\mathrm{H}^{+}\right]$(for acidic medium, slope $=0.76$ ), and $\log k_{\text {obs }}$ versus $\log \left[\mathrm{OH}^{-}\right]$(for alkaline medium, slope $=0.69$ ) as shown in Figures 3 and 4, respectively.

\subsection{Effect of Ionic Strengths on the Oxidation Rates}

The effect of ionic strengths of the reactions media was examined by varying the ionic strength between 2.0 and 4.0 moldm ${ }^{-3}$ in acidic medium and between 0.2 and $0.4 \mathrm{~mol} \mathrm{dm}^{-3}$ in alkaline medium using sodium perchlorate at fixed concentrations of the reactants and with other conditions constant. The results listed in Table 1 indicated that increasing ionic strength in both acidic and alkaline media had no significant effecton the oxidation rates.

\subsection{Free Radicals Tests}

The intervention of free radical intermediate during the oxidation reaction was examined by addition of known quantities of acrylonitrile monomer to the reactions mixtures in all media which were kept in an inert atmosphere for about 6 hours at room temperature. When the reactions mixtures were diluted with methanol, progressive white precipitates were formed suggesting intervention of free radicals in the oxidation reactions. When the experiments were repeated in the absence of the cadaverine under similar conditions, the tests were negative. This indicates that the reactions were routed through free radical paths. 
Table 1. Effects of variation of $\left[\mathrm{MnO}_{4}^{-}\right],[\mathrm{CAD}],\left[\mathrm{H}^{+}\right]$(in acid medium), $[\mathrm{OH}]$ (in alkaline medium), and ionic strength, I, on the observed-first order rate constants $\left(k_{o b s}\right)$ in the oxidation of cadaverine by permanganate ion in acidic, neutral and alkaline media at $25^{\circ} \mathrm{C}$.

\begin{tabular}{|c|c|c|c|c|c|c|c|}
\hline \multicolumn{2}{|c|}{ Neutral medium } & \multirow{2}{*}{$\begin{array}{l}10^{3}[\mathrm{CAD}] \\
\left(\mathrm{mol} \mathrm{dm}^{-3}\right)\end{array}$} & \multicolumn{2}{|c|}{ Acidic medium } & \multicolumn{2}{|c|}{ Alkaline medium } & \multirow{2}{*}{$\begin{array}{l}10^{5} k_{\text {obs }} \\
\left(\mathrm{s}^{-1}\right)\end{array}$} \\
\hline $\begin{array}{l}1^{4}\left[\mathrm{MnO}_{4}^{-}\right] \\
\left(\mathrm{mol} \mathrm{dm}^{-3}\right)\end{array}$ & $\begin{array}{l}10^{3}[\mathrm{CAD}] \\
\left(\mathrm{mol} \mathrm{dm}^{-3}\right)\end{array}$ & & $\begin{array}{l}{\left[\begin{array}{l}{\left[\mathrm{H}^{+}\right]} \\
(\mathrm{mol} \mathrm{dm}\end{array}\right)} \\
\end{array}$ & $\begin{array}{l}I \\
\left(\mathrm{~mol} \mathrm{dm}^{-3}\right)\end{array}$ & $\begin{array}{l}{\left[\mathrm{OH}^{-}\right]} \\
\left(\mathrm{mol} \mathrm{dm}^{-3}\right)\end{array}$ & $\begin{array}{l}I \\
\left(\mathrm{~mol} \mathrm{dm}^{-3}\right)\end{array}$ & \\
\hline 2.0 & 6.0 & & & & & & 169.3 \\
\hline 4.0 & 6.0 & & & & & & 166.5 \\
\hline 6.0 & 6.0 & & & & & & 165.9 \\
\hline 8.0 & 6.0 & & & & & & 159.2 \\
\hline 10.0 & 6.0 & & & & & & 164.8 \\
\hline 0.5 & 2.0 & & & & & & 61.1 \\
\hline 1.0 & 4.0 & & & & & & 111.0 \\
\hline 1.5 & 6.0 & & & & & & 165.9 \\
\hline 2.0 & 8.0 & & & & & & 226.3 \\
\hline 2.5 & 10.0 & & & & & & 271.4 \\
\hline 4.0 & & 2.0 & 1.0 & 2.0 & & & 64.9 \\
\hline 4.0 & & 4.0 & 1.0 & 2.0 & & & 118.1 \\
\hline 4.0 & & 6.0 & 1.0 & 2.0 & & & 179.8 \\
\hline 4.0 & & 8.0 & 1.0 & 2.0 & & & 241.0 \\
\hline 4.0 & & 10.0 & 1.0 & 2.0 & & & 282.2 \\
\hline 4.0 & & 6.0 & 0.4 & 2.0 & & & 53.2 \\
\hline 4.0 & & 6.0 & 0.6 & 2.0 & & & 119.7 \\
\hline 4.0 & & 6.0 & 1.0 & 2.0 & & & 179.8 \\
\hline 4.0 & & 6.0 & 1.4 & 2.0 & & & 229.5 \\
\hline 4.0 & & 6.0 & 1.8 & 2.0 & & & 263.7 \\
\hline 4.0 & & 6.0 & 1.0 & 2.0 & & & 179.8 \\
\hline 4.0 & & 6.0 & 1.0 & 2.5 & & & 182.9 \\
\hline 4.0 & & 6.0 & 1.0 & 3.0 & & & 177.1 \\
\hline 4.0 & & 6.0 & 1.0 & 3.5 & & & 175.0 \\
\hline 4.0 & & 6.0 & 1.0 & 4.0 & & & 183.6 \\
\hline 4.0 & & 2.0 & & & 0.10 & 0.10 & 55.3 \\
\hline 4.0 & & 4.0 & & & 0.10 & 0.10 & 102.7 \\
\hline 4.0 & & 6.0 & & & 0.10 & 0.10 & 154.6 \\
\hline 4.0 & & 8.0 & & & 0.10 & 0.10 & 209.8 \\
\hline 4.0 & & 10.0 & & & 0.10 & 0.10 & 254.1 \\
\hline 4.0 & & 6.0 & & & 0.02 & 0.10 & 49.8 \\
\hline 4.0 & & 6.0 & & & 0.06 & 0.10 & 113.2 \\
\hline 4.0 & & 6.0 & & & 0.10 & 0.10 & 154.6 \\
\hline 4.0 & & 6.0 & & & 0.14 & 0.10 & 197.9 \\
\hline 4.0 & & 6.0 & & & 0.18 & 0.10 & 223.7 \\
\hline 4.0 & & 6.0 & & & 0.10 & 0.20 & 154.6 \\
\hline 4.0 & & 6.0 & & & 0.10 & 0.25 & 157.8 \\
\hline 4.0 & & 6.0 & & & 0.10 & 0.30 & 160.1 \\
\hline 4.0 & & 6.0 & & & 0.10 & 0.35 & 155.4 \\
\hline 4.0 & & 6.0 & & & 0.10 & 0.40 & 156.3 \\
\hline
\end{tabular}

Experimental error $\pm 3 \%$ 


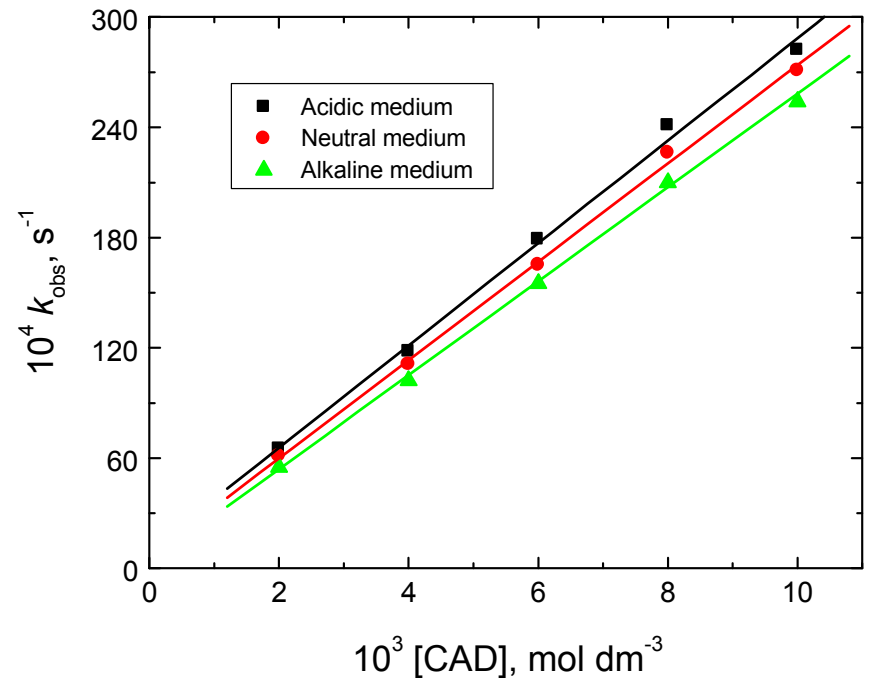

Figure 2. Plots of $k_{\text {obs }}$ versus [CAD] in the oxidation of cadaverine by permanganate ion in acidic medium $\left(\left[\mathrm{H}^{+}\right]=1.0\right.$ and $\left.I=2.0 \mathrm{~mol} \mathrm{dm}^{-3}\right)$, neutral, and alkaline medium $\left(\left[\mathrm{OH}^{-}\right]=0.1\right.$ and $\left.\mathrm{I}=0.2 \mathrm{~mol} \mathrm{dn}^{-3}\right)$. $\left[\mathrm{MnO}_{4}^{-}\right]=4.0 \times 10^{-4}$ at $25^{\circ} \mathrm{C}$.

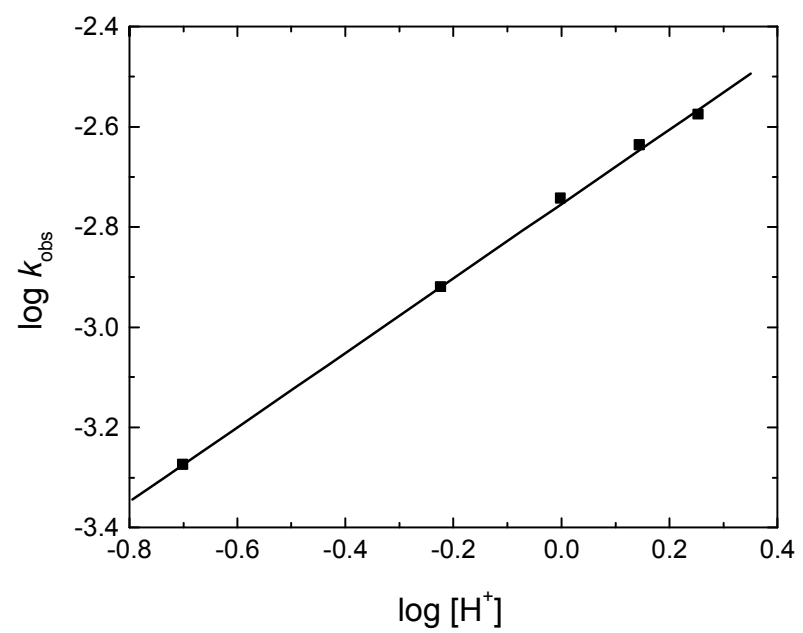

Figure 3. Plot of $\log k_{\text {obs }}$ versus $\log \left[\mathrm{H}^{+}\right]$in the oxidation of cadaverine by permanganate ion in acidicmedium. $[\mathrm{CAD}]=6.0 \times 10^{-3},\left[\mathrm{MnO}_{4}^{-}\right]=4.0 \times 10^{-4}$ and $I=2.0 \mathrm{~mol} \mathrm{dm}^{-3}$ at $25^{\circ} \mathrm{C}$

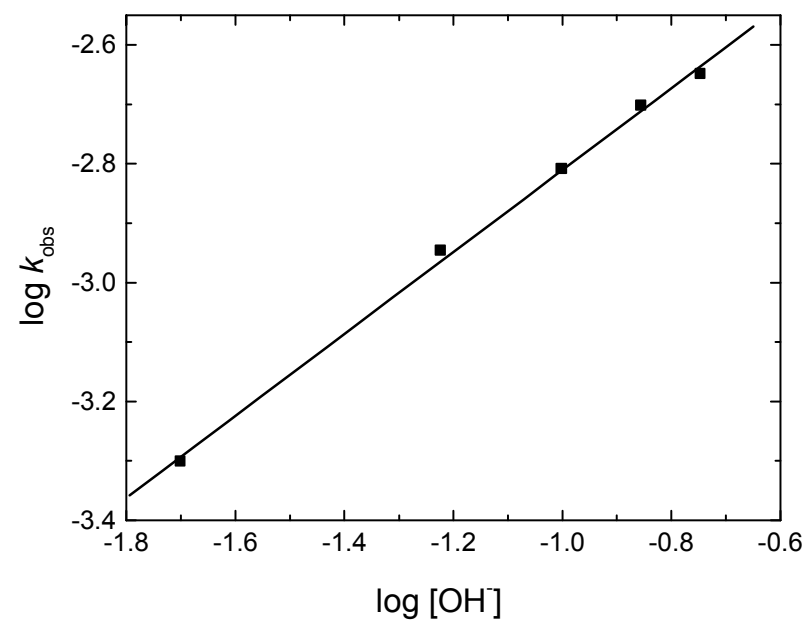

Figure 4. Plot of $\log k_{\text {obs }}$ versus $\log [\mathrm{OH}]$ in the oxidation of cadaverine by permanganate ion in alkaline medium. $[\mathrm{CAD}]=6.0 \times 10^{-3},\left[\mathrm{MnO}_{4}^{-}\right]=4.0 \times 10^{-}$ ${ }^{4}$ and $\mathrm{I}=0.2 \mathrm{~mol} \mathrm{dm}^{-3}$ at $25^{\circ} \mathrm{C}$.

\subsection{Mechanism of Oxidation in Acid Medium}

In acidic medium, the observed enhancement of the oxidation rate upon increasing the acid concentration with a less than unit order dependence on $\left[\mathrm{H}^{+}\right]$suggests $[17,21]$ protonation of permanganate ion to form permanganic acid $\left(\mathrm{HMnO}_{4}\right)$ which considered as a more powerful oxidant as illustrated by the first equilibrium in Scheme 2. The protonation of permanganate ion shifts the $\mathrm{Mn}^{\mathrm{VII}} / \mathrm{Mn}^{\mathrm{VI}}$ couple to a more positive value $(+1.3 \mathrm{~V})$, which makes $\mathrm{HMnO}_{4}$ a stronger oxidizing agent than $\mathrm{MnO}_{4}^{-}[21]$. On the other hand, the obtained less than unit order dependence with respect to [CAD] suggests formation of an intermediate complex between permanganate and cadaverine prior to the ratedetermining step. The kinetic evidence that supports complex formation may be represented by the linearity of the plot of $1 / k_{\text {obs }}$ versus $1 /[\mathrm{CAD}]$ (Fig. 5), similar to the well-known Michaelis-Menten [22] mechanism for enzyme-substrate reactions. The negligible effect of ionic strengthon the oxidation rate confirmed that the reaction occurred between two neutral molecules [23, 24], i.e. between $\mathrm{HMnO}_{4}$ and CAD. The cleavage of such complex leads to the formation of a free radical derived from cadaverine and an intermediate $\mathrm{Mn}(\mathrm{VI})$ species. Such intermediate is rapidly attacked by manganate (VI) ion to yield the final oxidation products of cadaverine and $\mathrm{Mn}$ (V) intermediate species. In further fast step the intermediate $\mathrm{Mn}(\mathrm{V})$, being very reactive and unstable, reacts with another molecule of cadaverine to give rise to the oxidation products of cadaverine and an intermediate Mn (III) species. This step is further followed by a reaction between two molecules of cadaverine and another molecule of permanganate to give the oxidation products of cadaverine and Mn (III) intermediate species. Finally, the fifth molecule of cadaverineis attacked by the formed twoMn (III) species leading to formation the oxidation products of cadaverine and $\mathrm{Mn}$ (II) as a final oxidation product of permanganate, satisfying the observed reaction stoichiometry. The proposed mechanism is illustrated in Scheme 2. 

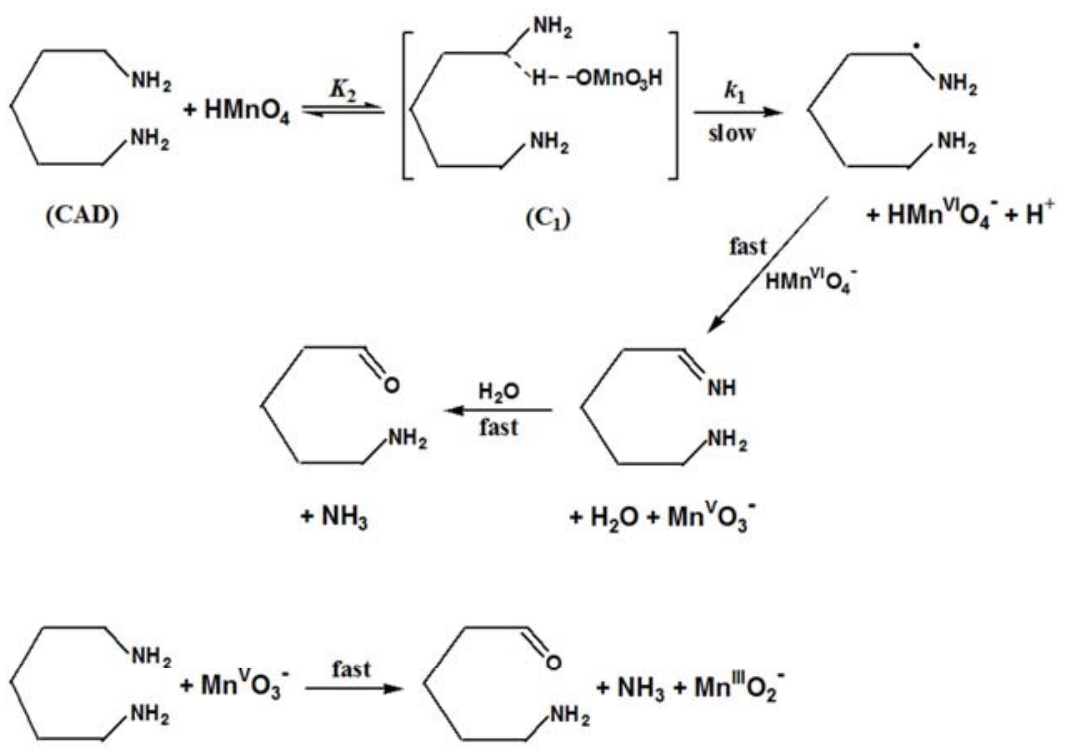

(CAD)
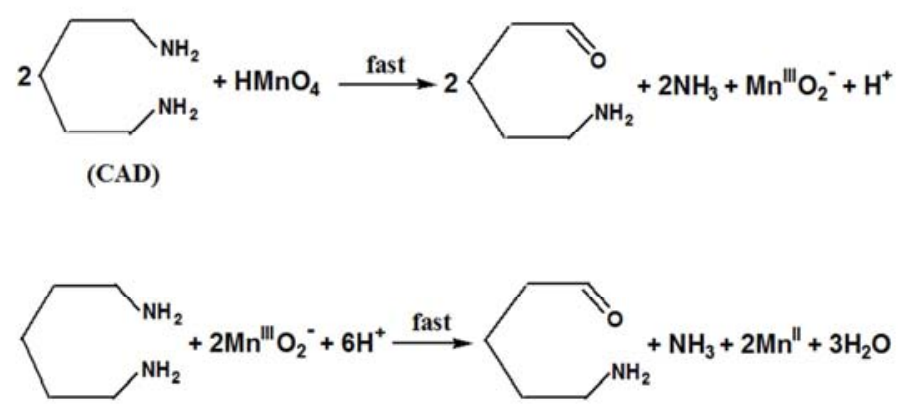

(CAD)

Scheme 2. Mechanism of oxidation of cadaverine by permanganate ion in acidic medium.

Based on the above-mentioned mechanism, the relationship between the rate of oxidation and the oxidant, substrate and hydrogen ion concentration was deduced to give the following rate-law expression:

$$
\text { Rate }=\frac{k_{1} K_{1} K_{2}\left[\mathrm{MnO}_{4}^{-}\right][\mathrm{CAD}]\left[\mathrm{H}^{+}\right]}{1+K_{1}\left[\mathrm{H}^{+}\right]+K_{1} K_{2}[\mathrm{CAD}]\left[\mathrm{H}^{+}\right]}
$$

Under pseudo-first order condition, the rate-law can be expressed by Eq. (5)

$$
\text { Rate }=\frac{-d\left[\mathrm{MnO}_{4}^{-}\right]}{d t}=k_{\mathrm{obs}}\left[\mathrm{MnO}_{4}^{-}\right]
$$

Comparing Eqs. (4) and (5) and rearrangement, the following relationship is obtained:

$$
\frac{1}{k_{o b s}}=\left(\frac{1+K_{1}\left[\mathrm{H}^{+}\right]}{k_{1} K_{1} K_{2}\left[\mathrm{H}^{+}\right]}\right) \frac{1}{[\mathrm{CAD}]}+\frac{1}{k_{1}}
$$

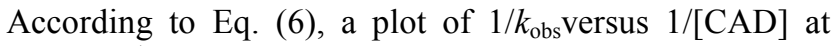
constant $\left[\mathrm{H}^{+}\right]$should be straight line with a positive intercept on $1 / k_{\mathrm{obs}}$ axis as observed experimentally (Fig. 5). From the intercept of such plot, the value of the rate constant of the slow step, $k_{1}$, was determined as $0.16 \mathrm{~s}^{-1}$.

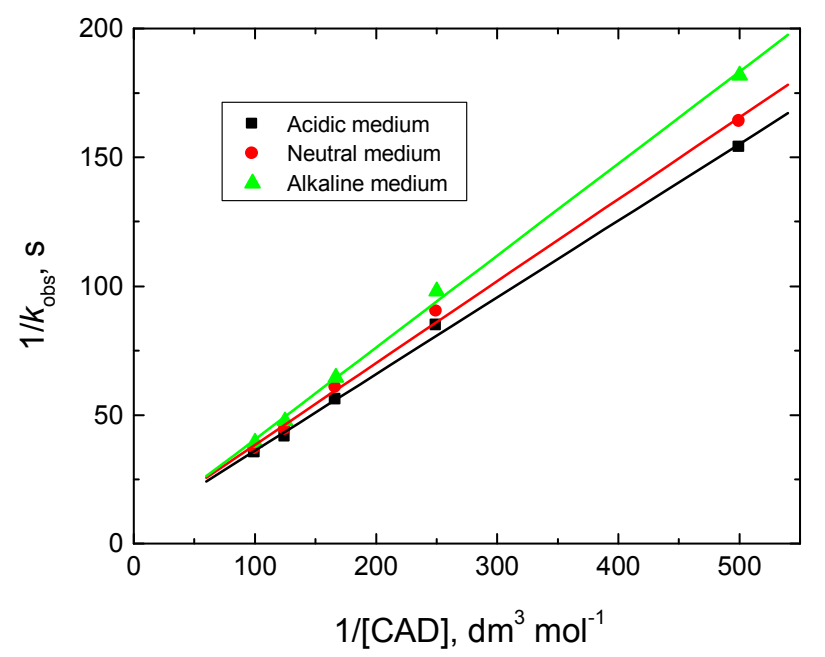

Figure 5. Plots of $1 / k_{\text {obs }}$ versus $1 /[C A D]$ in the oxidations of cadaverine by permanganate ion in acidic medium $\left(\left[\mathrm{H}^{+}\right]=1.0\right.$ and $\left.I=2.0 \mathrm{~mol} \mathrm{dm}^{-3}\right)$, neutral medium, and alkaline medium ([OH $]=0.1$ and $\left.\mathrm{I}=0.2 \mathrm{~mol} \mathrm{dn}^{-3}\right) .\left[\mathrm{MnO}_{4}^{-}\right]=4.0$ $x 10^{-4}$ at $25^{\circ} \mathrm{C}$. 
The small intercept manifested in Figure 5 leads to simplify Eq. (6) to the following equation:

$$
\frac{[\mathrm{CAD}]}{k_{o b s}}=\left(\frac{1}{k_{1} K_{1} K_{2}}\right) \frac{1}{\left[\mathrm{H}^{+}\right]}+\frac{1}{k_{1} K_{2}}
$$

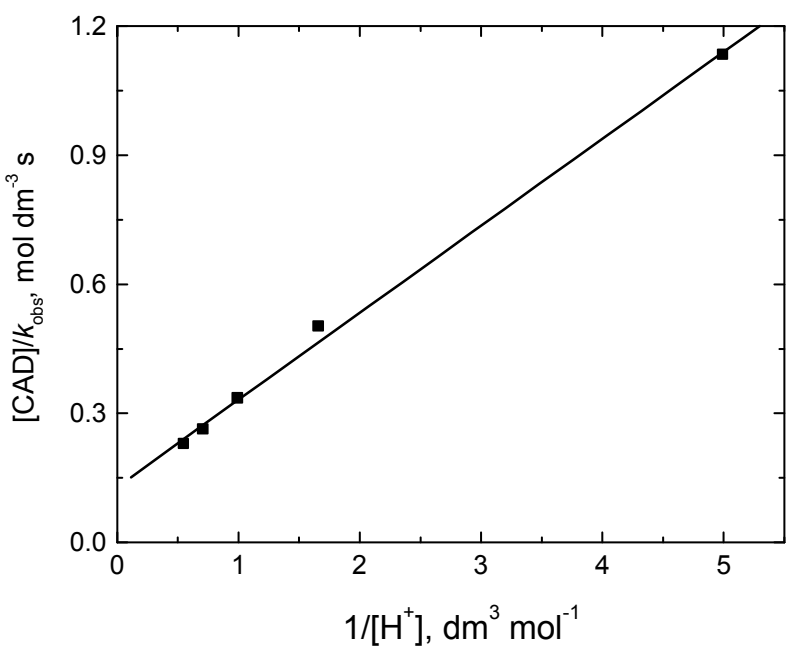

Figure 6. Verification of Eq. (7) in the oxidation of cadaverine by permanganate ion in acidic medium. $\left[\mathrm{MnO}_{4}^{-}\right]=4.0 \times 10^{-4}$ and $\mathrm{I}=2.0 \mathrm{~mol} \mathrm{dn^{-3 }}$ at $25^{\circ} \mathrm{C}$.
Therefore, a plot of $[\mathrm{CAD}] / k_{\text {obs versus } 1 /\left[\mathrm{H}^{+}\right] \text {at constant }}$ [CAD] should give a straight line with a positive intercept as obtained experimentally (Fig. 6). From the slope and intercept of such plot, the values of $K_{1}$ and $K_{2}$ were calculated as 0.65 and $48.08 \mathrm{dm}^{3} \mathrm{~mol}^{-1}$, respectively. The value of $K_{1}$ (protonation constant of permanganate ion) was found to in agreement with that reported earlier $[25,26]$.

\subsection{Mechanism of Oxidation in Neutral Medium}

The reaction between cadaverine and permanganate in neutral medium has a stoichiometry of $3: 2\left(\mathrm{CAD}: \mathrm{MnO}_{4}{ }^{-}\right)$ with a first-order dependence on $\left[\mathrm{MnO}_{4}^{-}\right]$, less than unit order in $[\mathrm{CAD}]$. Based on the experimental results, permanganate ion is suggested to react with one mole of cadaverinein a preequilibrium step to give a complex $\left(\mathrm{C}_{2}\right)$. The linearity of the plot of $1 / k_{\text {obs }}$ and $1 /[\mathrm{CAD}]$, Fig. 5, is considered as a kinetic evidence for such complex formation. Spectroscopic evidence for the complex formation was obtained from the UV-Vis spectra, Fig. 1b. The cleavage of such complex leads to the formation of a free radical intermediate of cadaverine and Mn (VI) followed by other fast steps (as discussed in case of acidic medium) to give rise to the final oxidation product as illustrated in Scheme 3.
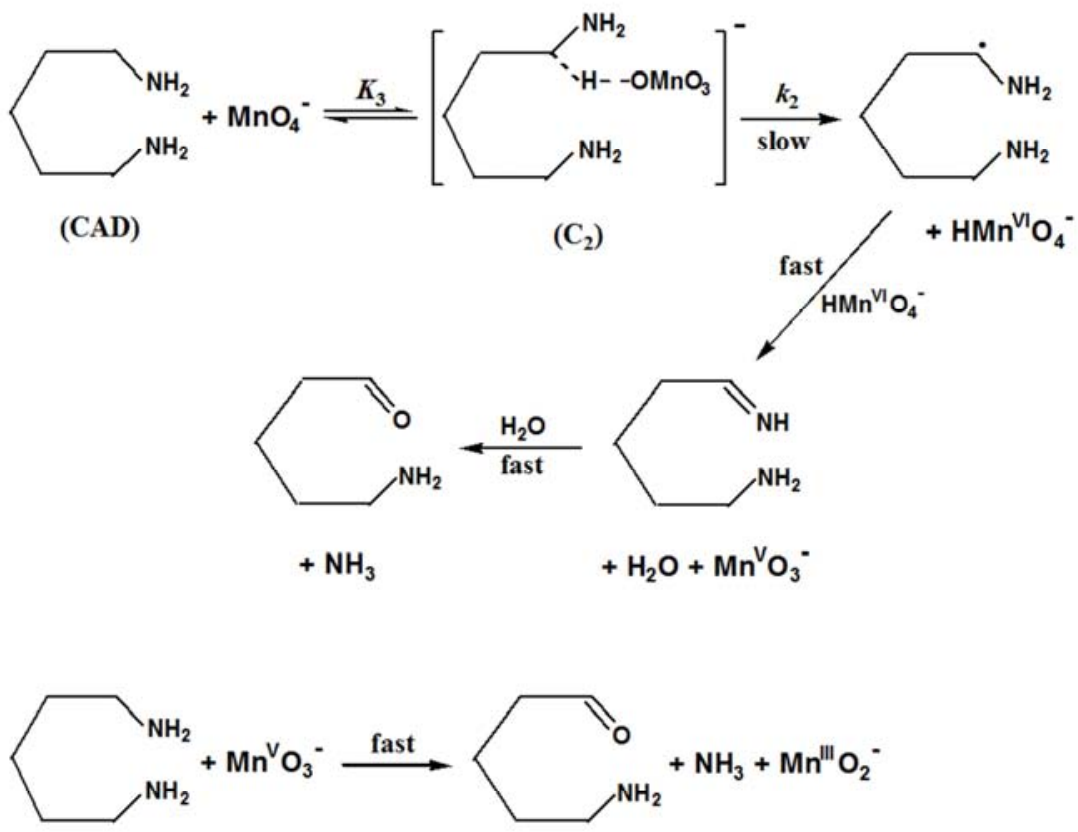

(CAD)

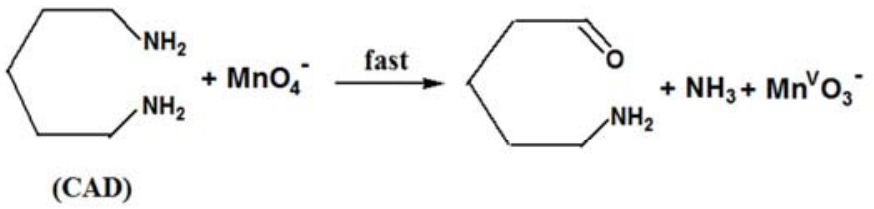

$\mathrm{Mn}^{\vee} \mathrm{O}_{3}^{-}+\mathrm{Mn}^{\mathrm{II}} \mathrm{O}_{2}^{-}+\mathrm{H}_{2} \mathrm{O}=2 \mathrm{MnO}_{2}+2 \mathrm{OH}^{-}$

Scheme 3. Mechanism of oxidation of cadaverine by permanganate ion in neutral medium. 
According to the mechanistic Scheme 3, the following rate law expressionwas deduced:

$$
\text { Rate }=\frac{k_{2} K_{3}[\mathrm{CAD}]\left[\mathrm{MnO}_{4}^{-}\right]}{1+K_{4}[\mathrm{CAD}]}
$$

Under pseudo-first order conditions, the rate-law can be expressed as:

$$
\text { Rate }=\frac{-d\left[\mathrm{MnO}_{4}^{-}\right]}{d t}=k_{\text {obs }}\left[\mathrm{MnO}_{4}^{-}\right]
$$

Comparing Eqs (8) and (9), and with rearrangement the following relationship is obtained:

$$
\frac{1}{k_{\mathrm{obs}}}=\left(\frac{1}{k_{2} K_{3}}\right) \frac{1}{[\mathrm{CAD}]}+\frac{1}{k_{2}}
$$

According to Eq. (10), a plot of $1 / k_{\text {obs }}$ versus $1 /[\mathrm{CAD}]$ should be linear with a positive intercept on $1 / k_{\text {obs }}$ axis as observed experimentally (Fig. 5). From the intercept and slope of such plot, the rate constant value of the slow step, $k_{2}$, and the formation constant of the intermediate complex, $K_{3}$, were determined as $0.15 \mathrm{~s}^{-1}$ and $20.56 \mathrm{dm}^{3} \mathrm{~mol}^{-1}$, respectively.

\subsection{Mechanism of Oxidation in Alkaline Medium}

In aqueous alkaline medium [27, 28] permanganate ion first combines with alkali to form an alkali-permanganate species in a pre-rate-determiming step, as described by the first equilibrium in Scheme 4. This is consistent with the apparent order of less than unity in $\mathrm{OH}^{-}$. Furthermore, the formation of $\left[\mathrm{MnO}_{4} \cdot \mathrm{OH}\right]^{2-}$ is supported by the plot of

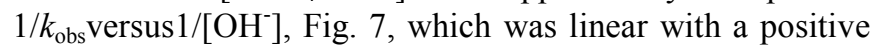
intercept.

In view of the above arguments, the following reaction mechanismcan be suggested which involve attack of the active species of permanganate, $\left[\mathrm{MnO}_{4} \cdot \mathrm{OH}\right]^{2-}$, on cadaverine leading to the formation of a complex $\left(\mathrm{C}_{3}\right)$ in a prior ratedetermining step. This was confirmed, as discussed before, by both spectroscopic evidence (Fig. 1c) and kinetic evidence (Fig. 5). The complex decomposes leading to formation of a free radical intermediatederived from cadaverine and $\mathrm{Mn}$ (VI) intermediate. This intermediate is rapidly attacked by another moleculeof the oxidant to yield the final oxidation products. The suggested mechanism is illustrated in the following sequence (Scheme 4):

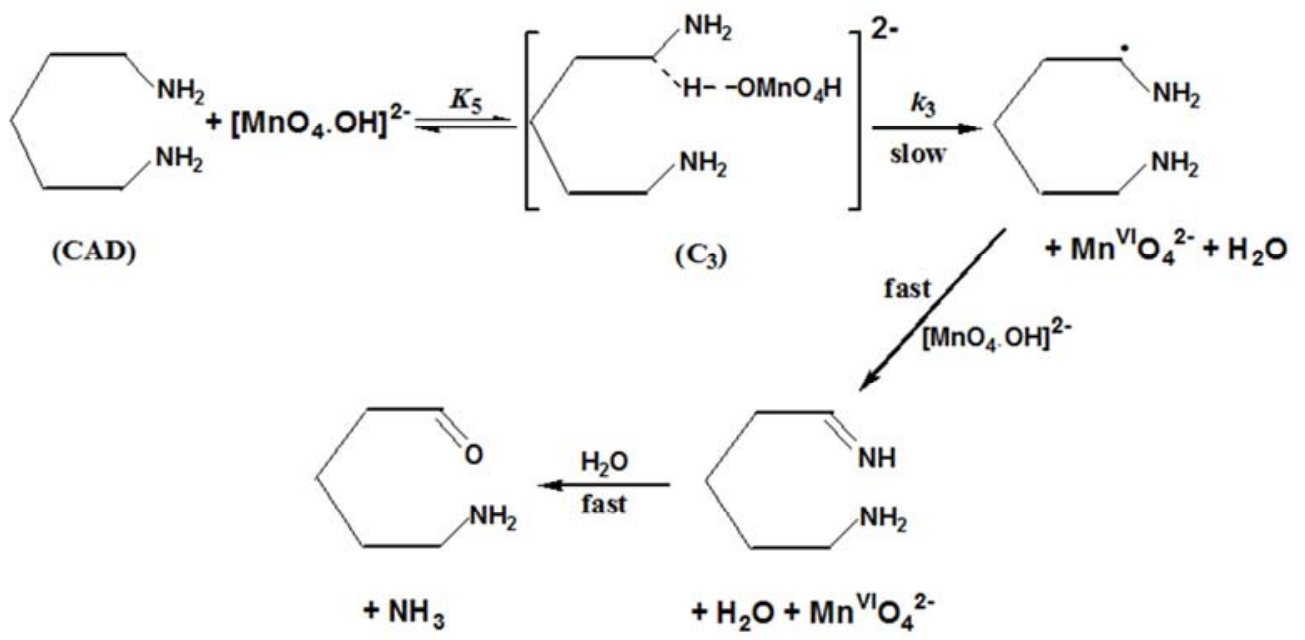

Scheme 4. Mechanism of oxidation of cadaverine by permanganate ion in alkaline medium.

Owing to the above-mentioned mechanism, the rate of oxidation can be expressed by the following rate-law equation:

$$
\text { Rate }=\frac{-d\left[\mathrm{MnO}_{4}^{-}\right]}{d t}=k_{3}\left[\mathrm{C}_{3}\right]
$$

The rate law expressed the change of the oxidation rate with the substrate, hydroxyl ion and oxidant concentrations was deduced (See Appendix 3) to give the following equation:

$$
\text { Rate }=\frac{k_{3} K_{4} K_{5}[\mathrm{CAD}]\left[\mathrm{OH}^{-}\right]\left[\mathrm{MnO}_{4}^{-}\right]}{1+K_{4}\left[\mathrm{OH}^{-}\right]+K_{4} K_{5}[\mathrm{CAD}]\left[\mathrm{OH}^{-}\right]}
$$

Under pseudo-firstorder condition, the ratelaw can be expressed by Eq (13),

$$
\text { Rate }=\frac{-d\left[\mathrm{MnO}_{4}^{-}\right]}{d t}=k_{\text {obs }}\left[\mathrm{MnO}_{4}^{-}\right]
$$

Comparing Eqs (12) and (13) and rearrangement, the following two equations are obtained:

$$
\frac{1}{k_{\text {obs }}}=\left(\frac{1+K_{4}\left[\mathrm{OH}^{-}\right]}{k_{3} K_{4} K_{5}\left[\mathrm{OH}^{-}\right]}\right) \frac{1}{[\mathrm{CAD}]}+\frac{1}{k_{3}}
$$

Equation (14) requires that the relationship between $1 / k_{\text {obs }}$ and $1 /[\mathrm{CAD}]$ at constant $\left[\mathrm{OH}^{-}\right]$to be linear with a non-zero intercept on the $1 / k_{\mathrm{obs}}$ axis as was experimentally satisfied 
(Fig. 5), from the intercept of such plot, thevalue of the rate constant of the slow step $\left(k_{3}\right)$ was evaluated as $0.21 \mathrm{~s}^{-1}$. Also, regarding to Eq. (15), the plot of $1 / k_{\text {obs }}$ versus $1 /\left[\mathrm{OH}^{-}\right]$at constant $[\mathrm{CAD}]$ also should give a straight line with a positive intercept on $1 / k_{\text {obs }}$ axis as was experimentally observed, Fig 7 . Values of the equilibrium constants; $K_{4}$ and $K_{5}$ were calculated from the slope and intercept of such plot (and the obtained $k_{3}$ value) as 13.09 and $131.78 \mathrm{dm}^{3} \mathrm{~mol}^{-1}$. The value of $K_{4}$ was found to be in a good agreement with that reported in earlier works [7].

The small intercept obtained in Figure 5 leads to simplify Eq. (14) to the following equation:

$$
\frac{[\mathrm{CAD}]}{k_{\text {obs }}}=\left(\frac{1}{k_{3} K_{4} K_{5}}\right) \frac{1}{\left[\mathrm{OH}^{-}\right]}+\frac{1}{k_{3} K_{5}}
$$

Also, a plot of $[\mathrm{CAD}] / k_{\mathrm{obs}}$ versus $1 /\left[\mathrm{OH}^{-}\right]$at constant [CAD] should give a straight line with a positive intercept as obtained experimentally (Fig. 7). From the slope and intercept of such plot, the values of $K_{4}$ and $K_{5}$ were calculated as 7.85 and $28.79 \mathrm{dm}^{3} \mathrm{~mol}^{-1}$, respectively. The value of $K_{4}$ (formation constant of alkali-permanganate) was found to in agreement with that reported earlier [25, 26].

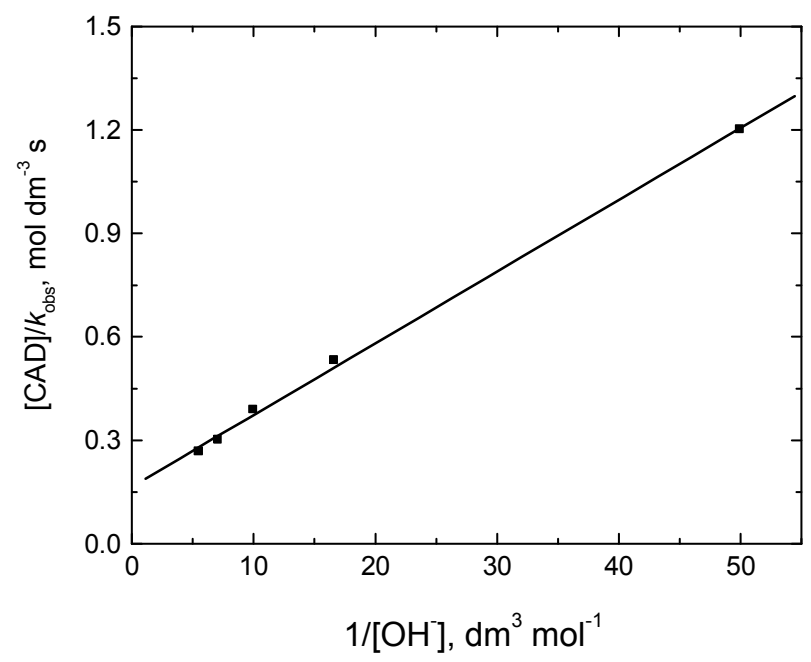

Figure 7. Plot of $1 / k_{\text {obs }}$ versus $1 /[\mathrm{OH}]$ in theoxidation of cadaverine by permanganate ion in alkaline medium. $[\mathrm{CAD}]=6.0 \times 10^{-3},\left[\mathrm{MnO}_{4}^{-}\right]=4.0 \times 10^{-}$ ${ }^{4}$ and $\mathrm{I}=0.2 \mathrm{~mol} \mathrm{dm} \mathrm{m}^{-3}$ at $25^{\circ} \mathrm{C}$.

\section{Conclusion}

Kinetics and mechanistic study of permanganate oxidations of cadaverine was carried out in acidic, neutral and alkaline media. Under our experimental conditions, $\mathrm{HMnO}_{4}, \mathrm{MnO}_{4}^{-}$ and $\left[\mathrm{MnO}_{4} \cdot \mathrm{OH}\right]^{2-}$ are regarded as the kinetically reactive species of permanganate ion in acidic, neutral and alkaline media, respectively. The final oxidation products of cadaverine in all three media were identified as 5-aminopropanal and ammonia. The appropriate rate-law expressions were deduced and the reactions constants involved in the different steps of the mechanisms were evaluated.

\section{References}

[1] Lewis, Robert Alan (1998). Lewis' Dictionary of Toxicology. CRC Press, p. 212.

[2] Yeoman CJ, et al (2013). A multi-omic systems-based approach reveals metabolic markers of bacterial vaginosis and insight into the disease, PloS one 8: e56111.

[3] Fawzy A, Ashour SS, Musleh MA (2014) Base-catalyzed oxidation of L-asparagine by alkaline permanganate and the effect of alkali-metal ion catalysts: kinetics and mechanistic approach, React. Kinet. Mech. Catal. 111: 443-460.

[4] Fawzy A, Shaaban MR (2014) Kinetic and mechanistic investigations on the oxidation of N'-heteroaryl unsymmetrical formamidines by permanganate in aqueous alkaline medium. Transition Met. Chem. 39: 379-386.

[5] Fawzy A, Zaafarany IA, Alfahemi J, Tirkistani FA (2015) Base-catalyzed oxidation of aminotriazole derivative by permanganate ion in aqueous alkaline medium: a kinetic study. Int. J. Inn. Res. Sci. Eng. Tech. 4: 6802-6814.

[6] Asghar BH, Fawzy A (2016) Kinetic, mechanistic, and spectroscopic studies of permanganate oxidation of azinylformamidines in acidic medium, with autocatalytic behavior of manganese (II). J. Saudi Chem. Soc. 20: 561-569.

[7] Fawzy A, Ashour SS, Musleh MA (2014) Kinetics and mechanism of oxidation of L-histidine by permanganate ions in sulfuric acid medium. Int. J. Chem. Kinet. 46: 370-381.

[8] Ahmed GA, Fawzy A, Hassan RM (2007) Spectrophotometric evidence for the formation of short-lived hypomanganate $(\mathrm{V})$ and manganate (VI) transient species during the oxidation of $K$-carrageenan by alkaline permanganate. Carbohydr. Res. 342: 1382-1386.

[9] Zaafarany IA, Fawzy A, Ahmed GA, Ibrahim SA, Hassan RM, Takagi HD (2010) Further evidence for detection of short-lived transient hypomanganate $(\mathrm{V})$ and manganate $(\mathrm{VI})$ intermediates during oxidation of some sulfated polysaccharides by alkaline permanganate using conventional spectrophotometeric techniques. Carbohydr. Res. 345: 15881593.

[10] Hassan RM, Fawzy A, Alarifi A, Ahmed GA, Zaafarany IA, Takagi HD (2011)Base-catalyzed oxidationof some sulfated macromolecules: kinetics and mechanism of formation of intermediate complexes of short-lived manganate (VI) and/or hypomanganate (V) during oxidation of iota-and lambdacarrageenan polysaccharides by alkaline permanganate. J. Mol. Catal. A 335: 38-45.

[11] Hassan RM, Dahy A, Ibrahim S, Zaafarany IA, Fawzy A (2012) Oxidation of some macromolecules. Kinetics and mechanism of oxidation of methyl cellulose polysaccharide by permanganate ion in acid perchlorate solutions. Ind. Eng. Chem. Res. 51: 5424-5432.

[12] Gardner KA, Kuehnert LL, Mayer JM (1997) Hydrogen atom abstraction by permanganate: oxidations of arylalkanes in organic solvents. Inorg. Chem. 36: 2069-2078.

[13] Kini AK, Farokhi SA, Nandibewoor ST (2002) A comparative study of ruthenium (III) catalysed oxidation of L-leucine and L-isoleucine by alkaline permanganate. A kinetic and mechanistic approach. Transition Met Chem. 27: 532-540. 
[14] Halligudi LL, Desai SM, Mavalangi AK, Nandibewoor ST (2000) Kinetics of the oxidative degradation of rac-serine by aqueous alkaline permanganate. Monatsh Chem. 131: 321-332.

[15] Verma RS, Reddy JM, Shastry VR (1974) Kinetic study of homogeneous acid-catalyzed oxidation of certain amino-acids by potassium permanganate in moderately concentrated acidic media. J. Chem. Soc. Perkin Trans. 124: 469-473.

[16] Mohanty B, Behera J, Acharya S, Mohanty P, Pantaik AK (2013) Metal ion catalyzed oxidation of L-lysine by alkaline permanganate Ion-A kinetic and mechanistic approach. Chem. Sci. Trans. 2: 51-60.

[17] Cotton FA, Wilkinson G. Advanced Inorganic Chemistry, p. 747, John Wiley and Sons, New York (1980).

[18] Vogel IA (1978) A Text Book of Quantitative Inorganic Analysis. $4^{\text {th }}$ edn, p. 352. ELBS, Longman.

[19] Feigl F (1975) Spot Tests in Organic Analysis, p. 195. Elsevier, New York.

[20] Vogel AI (1973) Text Book of Practical Organic Chemistry Including Quantitative Organic Analysis, $3^{\text {rd }}$ edn, p. 332. ELBS, Longman.

[21] Zahedi M, Bahrami H (2004) Kinetics and mechanism of the autocatalytic oxidation of L-asparagine in a moderately concentrated sulfuric acid medium. Kinet. Catal. 45: 351-358.
[22] Michaelis L, Menten ML (1913) The kinetics of invertase action. Biochem. Z. 49: 333-369.

[23] Amis ES (1966) Solvent Effect on Reaction Rates and Mechanism, Academic Press, New York, p. 28.

[24] Frost AA, Person RG (1970) Kinetics and mechanism, Wiley Eastern, New Delhi, p. 147.

[25] Hosahalli RV, Savanur AP, Nandibewoor ST, Chimatadar SA (2012) Kinetics and mechanism of the autocatalyzed oxidation of theophylline by permanganate in aqueous perchloric acid medium. J. Solution Chem. 41: 567-580.

[26] Farokhi SA, Nandibewoor ST (2004) The kinetic and mechanism of the oxidative decarboxylation of benzilic acid by acid permanganate (stopped flow technique)-autocatalytic study. Can. J. Chem. 82: 1372-1380.

[27] Panari RG, Chougale RB, Nandibewoor ST (1998) Oxidation of mandelic acid by alkaline potassium permanganate. A kinetic study. J. Phys. Org. Chem. 11: 448-454.

[28] De Oliveira LA, Toma HE, Giesbrecht E (1976) Kinetics of oxidation of free and coordinated dimethylsulfoxide with permanganate in aqueous solution. Inorg. Nucl. Chem. Lett. 2: 195-203. 